\title{
Bio-electrospraying assessment towards in situ chondrocyte-laden electrospun scaffold fabrication
}

\author{
Ângela Semitela ${ }^{1}$, Gonçalo Ramalhoํㅜ, Cátia Sousa², Alexandrina Mendes², Paula \\ Marques $^{1}$, and António Completo ${ }^{1}$ \\ ${ }^{1}$ University of Aveiro \\ ${ }^{2}$ University of Coimbra
}

September 11, 2020

\begin{abstract}
Electrospinning has been widely used for the development of fibrous scaffolds for cartilage tissue engineering (TE), however their small pores significantly limit cell infiltration throughout the scaffolds, particularly in three-dimensional (3D) designs. In this endeavor, a direct incorporation of chondrocytes into the fibers mesh during the electrospinning presents itself as a promising solution by use of bio-electrospraying. Yet, for this technology to be effectively employed for cartilage TE, it is necessary to assess if chondrocytes are in any way adversely affected. So, in this work, several electrospraying experiments were performed by adjusting various operational parameters to evaluate their influence on chondrocyte viability and function. A high percentage of post-electrosprayed chondrocytes remained viable upon the exposure of an external electric field generated by low needle to collector distances and low applied voltages. No obvious differences were found with non-electrosprayed chondrocytes in terms of viability, morphology and proliferation. The data reported here further suggest that bio-electrospraying under the optimal operational conditions might be a promising alternative to the existent cell seeding techniques, promoting not only cells safe delivery to the scaffold, but also the development of highly cellularized and uniform tissue constructs for cartilage repair.
\end{abstract}

\section{KEYWORDS}

Cartilage tissue engineering, Electrospraying, Chondrocyte, Needle gauge, Operational parameters

\section{INTRODUCTION}

Tissue engineering (TE) strategies have been actively seeking for an optimal approach for the development of suitable articular cartilage tissue replacements, given that the current treatment options do not constitute a feasible long-term solution (Correa \& Lietman, 2017). Considerable efforts have been made to improve scaffolds design - choice of material and fabrication technique, topography and three-dimensional (3D) anisotropic design - for functional cartilage tissue formation support, as well as effective cell incorporation and subsequent interaction of host cells within the construct (Camarero-Espinosa et al., 2016; Griffith \& Swartz, 2006). Electrospinning, for instance, has been widely employed for the fabrication of fibrous scaffolds for cartilage TE, not only due to its simplicity and versatility, but also the ECM-mimicking nanofibers produced, known to trigger a suitable chondrocyte response (Girão et al., 2018; Jin et al., 2018; Jun et al., 2018; McCullen et al., 2012; Reboredo et al., 2016; Steele et al., 2014). Still, the pores generated by electrospinning are usually too small to allow effective cell migration into the inner regions of the scaffold, particularly in 3D designs, resulting in poor and time dependent cellular infiltration, and ultimately, in the production of non-functional tissue constructs (Bueno et al., 2007; Griffon et al., 2011; Rnjak-Kovacina \& 
Weiss, 2011; Villalona et al., 2010). In this regard, a logical conclusion would be to directly incorporate the cells into the fibers mesh during scaffolds production in order to fabricate functional and homogeneous tissue constructs, by overcoming the challenges of cell infiltration through small pores by literally surrounding the cells with the fiber matrix as it is produced. Indeed, there are reports of successful development of cell-laden scaffolds by combining fiber electrospinning with cell electrospraying (Canbolat et al., 2011; H. Chen et al., 2015; Paletta et al., 2011; Stankus et al., 2006). Cell electrospraying, or bio-electrospraying, a concept first introduced in 2005 by Jayasingheet al, enables the deposition of living cells onto specific targets by exposing the cell suspension to an external high intensity electric field (Jayasinghe et al., 2006; Jayasinghe \& Townsend-Nicholson, 2006). The principle underlying electrospraying involves the application of voltage on a capillary holding the flow of liquid media, resulting in the ejection of a liquid microjet of charged droplets onto an oppositely charged collector. Moreover, when an electric potential difference threshold between the capillary and the collector is achieved, a stable conical liquid meniscus is formed - Taylor cone (Hartman et al., 1999; Kavadiya \& Biswas, 2018; Morad et al., 2016; Rosell-Llompart et al., 2018). Concerning cell electrospraying, the establishment of this stable cone-jet is crucial for the control of the precise cell placement, and it requires certain operational conditions, such as a particular flow rate, surface tension, conductivity and voltage (Hartman et al., 1999). Still, it is necessary to understand how the exposure to the electric field, as well as shear stress of passing through the cell electrospraying apparatus may affect cell viability and function. So far, neuronal cells (Eddaoudi et al., 2010; Jayasinghe \& Townsend-Nicholson, 2006; Townsend-Nicholson \& Jayasinghe, 2006), smooth muscle cells (Jayasinghe et al., 2007; Odenwälder et al., 2007; Patel et al., 2008), lymphocytes (Kempski et al., 2008), mononuclear cells (Hall et al., 2008), primary cardiac myocytes and endothelial cells (Barry et al., 2008; Ng et al., 2011), kidney cells (Kwok et al., 2008), embryonic stem cells (Abeyewickreme et al., 2009), mesenchymal stem cells (Mongkoldhumrongkul et al., 2009) to hematopoietic stem cells (Bartolovic et al., 2010), and even for multicellular organisms (Clarke \& Jayasinghe, 2008) have been electrosprayed and survived with no significant influence on a genetic, genomic and physiological level. Yet, so far, no study has reported the bio-electrospray of chondrocyte suspensions. So, the aim of the present study is to understand the impact of the electrospraying process and the respective parameters on the viability and proliferative behavior of chondrocytes, so that this technology might be implemented for the fabrication of chondrocyte-laden scaffolds for cartilage TE.

\section{MATERIALS AND METHODS}

\section{Electrospraying apparatus}

The experimental set-up is summarized in Fig. 1. All experiments were performed in a NANON 01 electrospinning machine (MECC; Fukuoka, Japan), thoroughly cleaned with 70 \% (v/v) ethanol beforehand. The remaining used instruments were already sterile or autoclaved before use. Stainless-steel needles with varying internal diameters (ID) were connected to a high voltage power supply with the ability to supply up to $30 \mathrm{kV}$. The needles were attached to cell suspension-containing $5 \mathrm{~mL}$ plastic syringes. The samples were collected in culture medium containing-wells of 24-well plates having ring-shaped copper grounded electrodes on its surface (Fig. 1a).

\section{Chondrocyte culture}

An immortalized human chondrocyte cell line C28/I2 (kindly provided by Prof. Mary Goldring, Hospital for Special Surgery, New York and Harvard University) was used. Cells were maintained at $37{ }^{\circ} \mathrm{C}$ in a humidified atmosphere of $5 \% \mathrm{CO}_{2}$ in air, in Dulbecco's Modified Eagle Medium (DMEM)/Nutrient Mixture F-12 Ham 1:1 v/v (DMEM: Gibco, Life Technologies; F-12: Sigma-Aldrich) supplemented with 10\% (v/v) non-heat-inactivated Fetal Bovine Serum (FBS; Gibco, Life Technologies), $1 \%$ (v/v) Penicillin/Streptomycin (P/S;Grisp). Medium refreshments were performed two times a week. Cells were harvested at pre-confluence using trypsin/EDTA solution (0.05\%/0.02\%, Sigma-Aldrich) for the electrospraying experiments. 


\section{Chondrocyte electrospraying}

$5 \mathrm{~mL}$ of Phosphate-Buffered Saline (PBS; Sigma Aldrich) supplemented with $2.5 \mu \mathrm{g} / \mathrm{mL}$ Amphotericin B was passed through the electrospraying apparatus. C28/I2 chondrocyte were split into three groups, each with $1 \times 10^{6}$ chondrocytes suspended in $300 \mu \mathrm{L}$ of culture medium with $0.25 \mu \mathrm{g} / \mathrm{mL}$ Amphotericin B (SigmaAldrich): culture controls (CC), which were maintained in the laminar flow hood at room temperature during the electrospraying process; needle control ( $\mathrm{NC})$, where the cell suspensions were subjected to the mechanical stress of passing through the electrospraying apparatus; and electrosprayed samples (E), where the cell suspensions were pumped through the electrospraying apparatus and exposed to voltage. Several electrospraying parameters were tested (Fig. 1b): three needle gauges (NG) $(25 \mathrm{G}-0.26 \mathrm{~mm} \mathrm{ID}, 27 \mathrm{G}-0.2$ $\mathrm{mm}$ ID and 30G-0.159 mm ID, all with $15 \mathrm{~mm}$ length), two needle to collector distances (NCD) (5 and $10 \mathrm{~cm}$ ), two applied voltages for each NG (applied voltages were selected based on the stability of the spray, i.e. lower and upper voltages of the stable cone-jet mode), and four flow rates (FR) $(1,2,5$ and $7 \mathrm{~mL} / \mathrm{h})$. A $n=5$ was considered for each group and for each electrospraying parameter test.

\section{Chondrocyte viability and morphology}

Collected samples were then incubated for 24 hours, after which chondrocyte viability was assessed using resazurin reduction assay. Briefly, a resazurin solution $(0.1 \mathrm{mg} / \mathrm{mL}$; ACROS Organics) in PBS was added to culture medium at a final concentration of $10 \%(\mathrm{v} / \mathrm{v})$, and chondrocytes were incubated in this solution at $37^{\circ} \mathrm{C}$ for $4 \mathrm{~h}$ in the dark, after which $100 \mu \mathrm{l}$ per well was transferred to a 96 -well plate and absorbance at 570 and $600 \mathrm{~nm}$ was measured. The final absorbance values for each sample were calculated as the ratio Abs570/Abs600 nm minus the Abs570/Abs600 nm ratio of a negative control (culture medium). The absorbance values of $\mathrm{CC}$ were then taken as $100 \%$ and cell viability calculated as a percentage of these control values. Chondrocyte morphology was visualized in an inverted optic microscope (Euromex, CMEX-PRO 10MP; Netherlands).

\section{Chondrocyte proliferative behavior}

The proliferative ability of the electrosprayed C28/I2 chondrocytes subjected to different NG and NCD parameters was assessed. Briefly, $2 \times 10^{4}$ electrosprayed C28/I2 chondrocytes were seeded in 48-well plates and cultured over a 14-day culture period, where medium changes were also performed two times a week.

At day 1, 7 and 14, chondrocyte viability and morphology were once more assessed as previously described.

\section{Statistical analysis}

All the quantitative data are expressed as mean \pm standard deviation. Statistical significance was determined, using OriginLab, by performing as suited One-way analysis of variance (ANOVA), One-way ANOVA with repeated measures, and Two-way ANOVA, all followed by post hoc Tukey's test. Significance was accepted at $p$-values inferior to $0.001,0.01$ and 0.05 .

\section{RESULTS}

\section{Establishment of electrospray stability}

Electrospray stability, identified here by the presence of the Taylor cone in the spray, as depicted in Fig. 2a, was assessed through a range of applied voltages, and the results are displayed in Fig. 2b. Stable cone-jet modes at $5 \mathrm{~cm}$ NCD were observed for $25 \mathrm{G}$ between 12 and $13 \mathrm{kV}$, for $27 \mathrm{G}$ between 9 and $11 \mathrm{kV}$, and for $30 \mathrm{G}$ between 8 and $12 \mathrm{kV}$. At $10 \mathrm{~cm}$, higher voltages were necessary to obtain a stable cone-jet mode $(p<$ 0.001 ), for all NG; indeed, for $25 \mathrm{G}$ this mode was observed between 15.5 and $16.5 \mathrm{kV}$, for $27 \mathrm{G}$ between 12 and $15 \mathrm{kV}$, and for $30 \mathrm{G}$ between 12 and $16 \mathrm{kV}$. Below the lower voltage of each range, no spray was produced, only droplets fell from the needle. Above the upper voltage value of each range reported, the spray was 
irregular and unstable, causing discontinuous jetting. A statistically significant difference was found between the voltage range of the $25 \mathrm{G}$ needle with the other NG for both NCD $(p<0.001$ at $5 \mathrm{~cm}$ and $p<0.01$ at 10 $\mathrm{cm})$. Also, wider stability voltage ranges were obtained with decreasing NG.

\section{Impact of electrospraying parameters on chondrocytes viability}

\section{Electrospraying process and needle gauge}

A statistically significant difference on the percentage of viable chondrocytes between $\mathrm{CC}$ and $\mathrm{E}$ groups was found for $25 \mathrm{G}(76 \pm 18 \% ; p<0.05)$ and for $30 \mathrm{G}(35 \pm 22 \% ; p<0.001)$ (Fig. 3a). Moreover, using a 30G needle, a reduction of the E cells' number was also observed in the $\mathrm{NC}$ in comparison with $\mathrm{CC}(68 \pm 10$ $\% ; p<0.05)$. Still, no differences were observed on the viability of the CC and NC groups when 25G (98 $\pm 5 \%$ ) and $27 \mathrm{G}$ needles $(99 \pm 2 \%$ ) were used (Fig. 3a). Regarding chondrocyte morphology, no visible differences were detected between $\mathrm{CC}$ and $\mathrm{NC}$ groups' viability. Additionally, the apparent number of visible chondrocytes on the micrographs was consistent with the viability results (Fig. 3b).

\section{Applied voltage}

Increasing the applied voltage at $5 \mathrm{~cm}$ - within the stable cone-jet mode - generated a considerable reduction of the viable $\mathrm{E}$ chondrocytes' percentage, when $25 \mathrm{G}$ (from $88 \pm 12$ to $60 \pm 11 \% ; p<0.001$ ) and 30G (from $53 \pm 15$ to $17 \pm 12 \%, p<0.001$ ) needles were used (Fig. 4a). On the contrary, no statistically significant differences were observed on chondrocyte viability using a $27 \mathrm{G} \mathrm{NG}$ (from $89 \pm 11 \%$ to $81 \pm 16 \%$ ). These results are corroborated by the apparent number of chondrocytes visible on the micrographs, which was considerably lower using a $30 \mathrm{G}$ needle (Fig. 4b). At $10 \mathrm{~cm}$, a similar behavior was observed for the 30G needle ( $28 \pm 2$ to $16 \pm 4 \%, p<0.05$; Fig. S1), while for the $25 \mathrm{G}(50 \pm 8$ to $44 \pm 5 \%)$ and $27 \mathrm{G}$ (48 \pm 9 to $39 \pm 11 \%$ ) needles, no significant differences were found (Fig. S1).

\section{Needle to collector distance}

A higher NCD $(10 \mathrm{~cm})$ substantially lowered the number of viable chondrocytes when 25G (from $76 \pm 18$ to $44 \pm 3 \% ; p<0.05$ ) and $27 \mathrm{G}$ (from $85 \pm 14$ to $44 \pm 11 \% ; p<0.001$ ) were employed, while for $30 \mathrm{G}$ NG group no statistically significant differences were found between the tested NCD (Fig. 5a). Furthermore, post-electrosprayed samples possessed significantly lower percentage of viable chondrocytes when the 30G was used $(35 \pm 22 \%$ at $5 \mathrm{~cm}, p<0.001$; and $21 \pm 7 \%$ at $10 \mathrm{~cm}, p<0.01$, Fig. 5a). These results are in agreement with the lower number of chondrocytes visible in the micrographs of the samples electrosprayed at $10 \mathrm{~cm}$ and with $30 \mathrm{G}$ (Fig.5b).

\section{Flow rate}

FR's impact on E C28/I2 chondrocytes was also assessed for a constant NG $(27 \mathrm{G})$ and NCD $(5 \mathrm{~cm})$ (Fig. 6). $2(86 \pm 6 \%)$ and $5(91 \pm 8 \%) \mathrm{mL} / \mathrm{h}$ allowed substantially higher number of viable post-electrosprayed chondrocytes, whereas $1 \mathrm{~mL} / \mathrm{h}$ resulted in extensive chondrocyte death $(4 \pm 2 \%, p<0.001$; Fig. 6a), which is also consistent with the fewer chondrocytes exhibited in the micrographs (Fig. 6b). Likewise, $7 \mathrm{~mL} / \mathrm{h}$ also generated a substantial reduction on the percentage of viable chondrocytes $(66 \pm 10 \% ; p<0.01)$.

\section{Influence of the electrospraying parameters on chondrocyte long-term prolifera- tive behavior}

The proliferative behavior of the electrosprayed C28/I2 chondrocytes was then assessed over a culture period of 14 days, where a significant increase on the percentage of viable post-electrosprayed chondrocytes was observed over time for all the NG and NCD combinations $(p<0.001 ;$ Fig. 7a). This behavior was also detected on the chondrocyte micrographs, where substantially more cells were found with increasing culture time (Fig. $7 \mathrm{~b}$ and Fig. S2). After 1 day of culture, significant differences were found between the NCD employed $(p<$ 
0.05). At day 7 , statistically significant differences were found on viable chondrocyte percentage between 25 and $27 \mathrm{NG}$ for both NCD tested $(p<0.05)$. Yet, by the end of the culture period no significant differences were observed between the number of the viable $\mathrm{E}$ chondrocytes subjected to all the parameters permutation (Fig. 7a). Furthermore, the morphological studies were indistinguishable between the CC and E samples, regardless of the NG and NCD combination (Fig. 7b and Fig. S2).

\section{DISCUSSION}

In an attempt to fabricate homogeneous and functional TE constructs, several reports have explored bioelectrospraying as an alternative for conventional cell seeding techniques in electrospun scaffolds (Sampson et al., 2013; Stankus et al., 2006; Weidenbacher et al., 2017). Yet, for chondrocyte electrospraying to be effectively employed for cartilage TE, it is of the utmost importance to assess if chondrocytes are in any way adversely affected. So, the present work seeks to understand the influence of the electrospraying technology on chondrocyte viability and function, as well as the establishment of optimal operational parameters for maximum chondrocyte viability.

First, and since this technology is to be used for the precise and uniform cell placement in 3D architectures for TE constructs (Jayasinghe \& Townsend-Nicholson, 2006; Stankus et al., 2006), jet stability should be achieved. Unlike previous reports (Hall et al., 2008; Jayasinghe et al., 2006; Odenwälder et al., 2007), it was possible to electrospray chondrocyte suspensions in a stable cone-jet mode, regardless of the NG and NCD. While it has been suggested that the cell suspension's high conductivity and low viscosity can be responsible for spray instability (Odenwälder et al., 2007), it is also believed that the effect of the nozzle geometry - in this case NG, electrode configuration and FR have an important role in the achievement of a stable cone-jet mode (Morad et al., 2016). In fact, the combination of a smaller NG, a higher NCD and a higher FR in this instance might have been a defining factor.

Upon the establishment of a stable spray, chondrocyte viability was evaluated for the variation of each electrospraying operational parameter. From the three NG tested, only $30 \mathrm{G}$ had a detrimental effect on chondrocytes - NC. It is possible that chondrocyte shearing whilst passing through the needle, particularly using $2 \mathrm{~mL} / \mathrm{h}$, was the reason for this effect, which is consistent with previous reports ( $\mathrm{Ng}$ et al., 2011; Ward et al., 2010). This chondrocyte mortality was exacerbated upon exposure to the electric field. A similar reduction on post-electrosprayed chondrocyte viability was observed for the $25 \mathrm{G}$ NG, while with $27 \mathrm{G}$ NG no significant harmful influence was observed. It is possible that the higher voltages required for spray stability on $25 \mathrm{G}$ needle had a somewhat adverse impact on the chondrocyte metabolism. As a matter of fact, increasing the system applied voltage systematically reduced chondrocyte viability. It has been suggested that high voltages, that generate strong electric fields, can induce pore formation and cell membrane damage, followed by an increased membrane permeabilization and, consequent cellular osmotic imbalance, ultimately resulting in cell death (Braghirolli et al., 2013; W. Chen et al., 1998; Sahoo et al., 2010). Moreover, beside electrical damages, strong electric fields can also incite thermal damage on the cells (W. Chen et al., 1998; Sahoo et al., 2010). Interestingly, this damage was not detected on the chondrocytes electrosprayed through a $27 \mathrm{G}$ needle, except when NCD was increased. In fact, a significant viability reduction was detected when chondrocytes were electrosprayed at $10 \mathrm{~cm}$. Several reports have noticed a similar behaviour. Paletta et al perceived an increased evaporation rate of the cell-laden droplets at higher NCD, ultimately resulting in an increased salt concentration, and therefore, reduced cell survival (Paletta et al., 2011). On the other hand, several authors have attributed greater cell loss to higher NCDs (Braghirolli et al., 2013; van Aalst et al., 2008; Ward et al., 2010). Additionally, the higher voltages required at higher NCD to maintain the electric field strength might, as previously mentioned, generated a cascade of events that contributed to cell death.

Regarding FR, it was possible to narrow the optimal values for maximum chondrocyte viability from 2 to 5 $\mathrm{mL} / \mathrm{h}$, particularly using a $27 \mathrm{G} \mathrm{NG}$ and $5 \mathrm{~cm} \mathrm{NCD}$. Above $5 \mathrm{~mL} / \mathrm{h}$, shear stresses played a significant role on chondrocyte mortality (Ng et al., 2011; Ward et al., 2010). Below $2 \mathrm{~mL} / \mathrm{h}$, it is believed that chondrocyte death was mainly due to the electrospraying duration. Indeed, electrospraying time using $1 \mathrm{~mL} / \mathrm{h}$ was 
18 minutes, while pumping at 2 and $5 \mathrm{~mL} / \mathrm{h}$ only 9 and 4 minutes were necessary, respectively. Besides the longer high voltages' submission time, the prolonged exposure to lower temperatures ( 25-27 oC) and $\mathrm{CO}_{2}$ concentration ( $0.04 \%$ ) may have contributed to chondrocyte death (Braghirolli et al., 2013; Paletta et al., 2011). Actually, Braghirolli et al performed an evaluation on electrosprayed cells with different electrospraying times and found that, while no differences were detected on cell viability, there were breaks in the DNA on the samples subjected to longer electrospraying periods (30 and $60 \mathrm{~min}$ ), indicating that prolonged electrospraying periods of time might provoke cellular genotoxicity (Braghirolli et al., 2013). Several reports have suggested the inclusion of a polymeric hydrogel onto the cell suspension in order to increase its viscosity, and reduce the impact of high voltages, dehydration and environmental conditions ( $\mathrm{H}$. Chen et al., 2015; Jayasinghe et al., 2011; Stankus et al., 2006; van Aalst et al., 2008).

Regardless of the electrospraying parameter permutation, electrosprayed chondrocyte were still able to attach to the tissue culture polystyrene and present their typical rounded to polygonal morphology (Goldring et al., 1994). Moreover, the percentage of viable chondrocytes submitted to certain electrospraying (27G NG and $5 \mathrm{~cm}$ NCD) parameters remained high - above $70 \%$. It should also be emphasized that while other studies have reported higher post-electrosprayed cell viabilities (above $80-90 \%$ ) (Andreu et al., 2012; Braghirolli et al., 2013; Ng et al., 2011; Sahoo et al., 2010; Sampson et al., 2013), it is important to mention that most of these employed substantially bigger NG and smaller NCD, which according to the herein reported data should render high viabilities. Additionally, different electrospraying conditions, viability assay sensitivity and cell susceptibility to damage may also be responsible for the observed difference (Paletta et al., 2011; Sahoo et al., 2010).

Interestingly, despite the fact that short-time viability assays disclosed the detrimental effect of several electrospraying parameters, the long-term proliferation studies revealed that no obvious differences between each parameter permutation and the respective $\mathrm{CC}$ were found in terms of gross morphology and rate of growth to confluence, generating two hypothesis: chondrocyte reduced viability was predominantly caused by chondrocyte loss within the electrospraying chamber; or chondrocytes were able to recover over the 14-day period. In fact, previous reports have found evidence of cellular DNA repair were found after only 5 hours. These results further suggest bio-electrospraying under the optimal operational conditions allows not only the successful delivery of healthy chondrocytes, but also, when used in combination with polymer electrospinning, the development of highly cellularized nanofibrous scaffolds for cartilage TE. In this instance, an alternated chondrocyte electrospraying and polymer electrospinning approach - combining smaller NCD and higher NCD, respectively - may be the best solution for maximum chondrocyte survival coupled with maximum polymer solvent evaporation. This "cell layering" approach has been already reported with successful cell incorporation, although bio-electrospraying was not always employed in this instance (Canbolat et al., 2011; Stankus et al., 2006; Xu et al., 2012).

Despite the promising results here reported, further characterization should be performed particularly regarding gene expression patterns to validate the biological efficacy of bio-electrospraying for cartilage TE applications. Although the use of an immortalized cell line C28/I2 in this instance may have been advantageous in assessing the optimal electrospraying operational parameters in terms of speed and reproducibility (Goldring et al., 1994; Greco et al., 2011), it may also present distinct degrees of sensitivity to the process, suggesting that bio-electrospraying studies should also be performed using primary chondrocytes to validate the use of this technology.

\section{CONCLUSIONS}

Here, an alternative seeding methodology has been proposed and evaluated to assess its possible use for a direct incorporation of chondrocytes onto electrospun scaffolds. Bio-electrospraying proved to be nondetrimental for chondrocytes under certain operational conditions. These include an intermediate NG (27G), not only to prevent cell shearing from a smaller NG, but also to avert the solicitation of higher voltages to establish a stable cone-jet mode from the higher NG; lower applied voltage $(9 \mathrm{kV})$, since higher voltages 
can induce electrical and thermal damages to the cells; smaller NCD $(5 \mathrm{~cm})$, to prevent cell desiccation and increase the number of recovered cells; and an intermediate FR (2 to $5 \mathrm{~mL} / \mathrm{h})$ to prevent not only the shear stress on the cells of higher FR, but also to reduce the electrospraying duration and, the consequent, prolonged exposure to the electric field and lower temperatures and $\mathrm{CO}_{2}$ concentrations. The long-term proliferation studies revealed that chondrocyte proliferative ability was not affected, regardless of the employed operational conditions. These results suggest that in fact this technology might be a promising alternative to the existent cell seeding techniques, promoting not only cells safe delivery to the scaffold, but also the development of highly cellularized and uniform tissue constructs for cartilage repair.

\section{ACKNOLEDGEMENTS}

This work was supported by the Portuguese funding of Program COMPETE-FEDER, Programa Operacional Competitividade e Internacionalizacao through the projects POCI-01-0145-FEDER-028424 and CENTRO01-0145-FEDER-022083. Also by Fundacao para a Ciencia e Tecnologia I.P. (FCT, IP) through the projects PTDC/EME-SIS/28424/2017, UIDB/00481/2020 and UIDP/00481/2020. The authors thank to FCT for the $\mathrm{PhD}$ grant SFRH/BD/133129/2017. The authors would also like to thank the valuable input of Andre F. Girao, Dr. Susana Pinto and Dr. Nuno Almeida.

\section{Conflict of Interests Statement}

The authors hereby certify that there are any conflicts of interests of any kind to declare.

\section{REFERENCES}

Abeyewickreme, A., Kwok, A., McEwan, J. R., \& Jayasinghe, S. N. (2009). Bio-electrospraying embryonic stem cells: Interrogating cellular viability and pluripotency. Integrative Biology , 1 (3), 260-266. https://doi.org/10.1039/b819889f

Andreu, N., Thomas, D., Saraiva, L., Ward, N., Gustafsson, K., Jayasinghe, S. N., \& Robertson, B. D. (2012). In vitro and in vivo interrogation of bio-sprayed cells. Small , 8 (16), 2495-2500. https://doi.org/10.1002/smll.201200138

Barry, S. P., Jayasinghe, S. N., Pericleous, C., Hubank, M., Latchman, D. S., \& Stephanou, A. (2008). Gene expression studies on bio-electrosprayed primary cardiac myocytes. Biotechnology Journal , 3 (4), 530-535. https://doi.org/10.1002/biot.200700266

Bartolovic, K., Mongkoldhumrongkul, N., Waddington, S. N., Jayasinghe, S. N., \& Howe, S. J. (2010). The differentiation and engraftment potential of mouse hematopoietic stem cells is maintained after bioelectrospray. Analyst, 135 (1), 157-164. https://doi.org/10.1039/b917813a

Braghirolli, D. I., Zamboni, F., Chagastelles, P. C., Moura, D. J., Saffi, J., Henriques, J. A. P., Pilger, D. A., \& Pranke, P. (2013). Bio-electrospraying of human mesenchymal stem cells: An alternative for tissue engineering. Biomicrofluidics , 7 (4), 1-12. https://doi.org/10.1063/1.4819747

Bueno, E. M., Laevsky, G., \& Barabino, G. A. (2007). Enhancing cell seeding of scaffolds in tissue engineering through manipulation of hydrodynamic parameters. Journal of Biotechnology , 129 (3), 516-531. https://doi.org/10.1016/j.jbiotec.2007.01.005

Camarero-Espinosa, S., Rothen-Rutishauser, B., Foster, E. J., \& Weder, C. (2016). Articular cartilage: From formation to tissue engineering. Biomaterials Science, 4 (5), 734-767. https://doi.org/10.1039/c6bm00068a

Canbolat, M. F., Tang, C., Bernacki, S. H., Pourdeyhimi, B., \& Khan, S. (2011). Mammalian cell viability in electrospun composite nanofiber structures. Macromolecular Bioscience , 11 (10), 1346-1356. https://doi.org/10.1002/mabi.201100108 
Chen, H., Liu, Y., \& Hu, Q. (2015). A novel bioactive membrane by cell electrospinning. Experimental Cell Research , 338 (2), 261-266. https://doi.org/10.1016/j.yexcr.2015.08.007

Chen, W., Han, Y., Chen, Y., \& Xie, J. T. (1998). Field-induced electroconformational damages in cell membrane proteins: A new mechanism involved in electrical injury. Bioelectrochemistry and Bioenergetics, 47 (2), 237-245. https://doi.org/10.1016/S0302-4598(98)00194-9

Clarke, J. D. W., \& Jayasinghe, S. N. (2008). Bio-electrosprayed multicellular zebrafish embryos are viable and develop normally.Biomedical Materials , 3 (1), 011001. https://doi.org/10.1088/1748-6041/3/1/011001

Correa, D., \& Lietman, S. A. (2017). Articular cartilage repair: Current needs, methods and research directions. Seminars in Cell and Developmental Biology , 62 , 67-77. https://doi.org/10.1016/j.semcdb.2016.07.013

Eddaoudi, A., Townsend-Nicholson, A., Timms, J. F., Schorge, S., \& Jayasinghe, S. N. (2010). Molecular characterisation of post-bio-electrosprayed human brain astrocytoma cells. Analyst ,135 (10), 2600-2612. https://doi.org/10.1039/c0an00213e

Girao, A. F., Semitela, A., Ramalho, G., Completo, A., \& Marques, P. A. A. P. (2018). Mimicking nature: Fabrication of 3D anisotropic electrospun polycaprolactone scaffolds for cartilage tissue engineering applications. Composites Part B: Engineering , 154 (August), 99-107. https://doi.org/10.1016/j.compositesb.2018.08.001

Goldring, M. B., Birkhead, J. R., Suen, L. F., Yamin, R., Mizuno, S., Glowacki, J., Arbiser, J. L., \& Apperley, J. F. (1994). Interleukin-1 beta-modulated gene expression in immortalized human chondrocytes. Journal of Clinical Investigation , 94 (6), 2307-2316. https://doi.org/10.1172/JCI117595

Greco, K. V, Iqbal, A. J., Rattazzi, L., Nalesso, G., Moradi-Bidhendi, N., Moore, A. R., Goldring, M. B., Dell'Accio, F., \& Perretti, M. (2011). High density micromass cultures of a human chondrocyte cell line: A reliable assay system to reveal the modulatory functions of pharmacological agents. Biochemical Pharmacology , 82 (12), 1919-1929. https://doi.org/10.1016/j.bcp.2011.09.009

Griffith, L. G., \& Swartz, M. A. (2006). Capturing complex 3D tissue physiology in vitro. Nature Reviews Molecular Cell Biology ,7 (3), 211-224. https://doi.org/10.1038/nrm1858

Griffon, D. J., Abulencia, J. P., Ragetly, G. R., Fredericks, L. P., \& Chaieb, S. (2011). A comparative study of seeding techniques and three-dimensionalmatrices for mesenchymal cell attachment. Journal of Tissue Engineering and Regenerative Medicine , 5 (3), 169-179. https://doi.org/10.1002/term.302

Hall, R. P., Ogilvie, C. M., Aarons, E., \& Jayasinghe, S. N. (2008). Genetic, genomic and physiological state studies on single-needle bio-electrosprayed human cells. Analyst , 133 (10), 1347-1351. https://doi.org/10.1039/b806901h

Hartman, R. P. A., Brunner, D. J., Camelot, D. M. A., Marijnissen, J. C. M., \& Scarlett, B. (1999). Electrohydrodynamic atomization in the cone-jet mode physical modeling of the liquid cone and jet.Journal of Aerosol Science , 30 (7), 823-849. https://doi.org/10.1016/S0021-8502(99)00033-6

Jayasinghe, S. N., Eagles, P. A. M., \& Qureshi, A. N. (2006). Electric field driven jetting: An emerging approach for processing living cells.Biotechnology Journal , 1 (1), 86-94. https://doi.org/10.1002/biot.200500025

Jayasinghe, S. N., Irvine, S., \& McEwan, J. R. (2007). Cell electrospinning highly concentrated cellular suspensions containing primary living organisms into cell-bearing threads and scaffolds. Nanomedicine , 2 (4), 555-567. https://doi.org/10.2217/17435889.2.4.555

Jayasinghe, S. N., \& Townsend-Nicholson, A. (2006). Stable electric-field driven cone-jetting of concentrated biosuspensions.Lab on a Chip , 6 (8), 1086-1090. https://doi.org/10.1039/b606508m 
Jayasinghe, S. N., Warnes, G., \& Scotton, C. J. (2011). Bio-electrosprayed living composite matrix implanted into mouse models.Macromolecular Bioscience , 11 (10), 1364-1369. https://doi.org/10.1002/mabi.201100131

Jin, G., He, R., Sha, B., Li, W., Qing, H., Teng, R., \& Xu, F. (2018). Electrospun three-dimensional aligned nanofibrous scaffolds for tissue engineering. Materials Science and Engineering C ,92 (November 2017), 995-1005. https://doi.org/10.1016/j.msec.2018.06.065

Jun, I., Han, H.-S., Edwards, J., \& Jeon, H. (2018). Electrospun Fibrous Scaffolds for Tissue Engineering: Viewpoints on Architecture and Fabrication. International Journal of Molecular Sciences ,19 (3), 745. https://doi.org/10.3390/ijms19030745

Kavadiya, S., \& Biswas, P. (2018). Electrospray deposition of biomolecules: Applications, challenges, and recommendations.Journal of Aerosol Science , 125 (May), 182-207. https://doi.org/10.1016/j.jaerosci.2018.04.009

Kempski, H., Austin, N., Roe, A., Chatters, S., \& Jayasinghe, S. N. (2008). Pilot study to investigate the possibility of cytogenetic and physiological changes in bio-electrosprayed human lymphocyte cells. Regenerative Medicine , 3 (3), 343-349. https://doi.org/10.2217/17460751.3.3.343

Kwok, A., Arumuganathar, S., Irvine, S., McEwan, J. R., \& Jayasinghe, S. N. (2008). A hybrid bio-jetting approach for directly engineering living cells. Biomedical Materials , 3 (2), 025008. https://doi.org/10.1088/1748-6041/3/2/025008

McCullen, S. D., Autefage, H., Callanan, A., Gentleman, E., \& Stevens, M. M. (2012). Anisotropic fibrous scaffolds for articular cartilage regeneration. Tissue Engineering Part A , 18 (19-20), 2073-2083. https://doi.org/10.1089/ten.tea.2011.0606

Mongkoldhumrongkul, N., Flanagan, J. M., \& Jayasinghe, S. N. (2009). Direct jetting approaches for handling stem cells. Biomedical Materials , 4 (1), 015018. https://doi.org/10.1088/1748-6041/4/1/015018

Morad, M. R., Rajabi, A., Razavi, M., \& Pejman Sereshkeh, S. R. (2016). A Very Stable High Throughput Taylor Cone-jet in Electrohydrodynamics.Scientific Reports , 6 (August), 1-10. https://doi.org/10.1038/srep38509

Ng, K. E., Joly, P., Jayasinghe, S. N., Vernay, B., Knight, R., Barry, S. P., McComick, J., Latchman, D., \& Stephanou, A. (2011). Bio-electrospraying primary cardiac cells: In vitro tissue creation and functional study. Biotechnology Journal , 6 (1), 86-95. https://doi.org/10.1002/biot.201000125

Odenwalder, P. K., Irvine, S., McEwan, J. R., \& Jayasinghe, S. N. (2007). Bio-electrosprays: A novel electrified jetting methodology for the safe handling and deployment of primary living organisms.Biotechnology Journal , 2 (5), 622-630. https://doi.org/10.1002/biot.200700031

Paletta, J. R. J., Mack, F., Schenderlein, H., Theisen, C., Schmitt, J., Wendorff, J. H., Agarwal, S., FuchsWinkelmann, S., \& Schofer, M. D. (2011). Incorporation of osteoblasts (MG63) into 3D nanofibre matrices by simultaneous electrospinning and spraying in bone tissue engineering.European Cells and Materials , 21 , 384-395. https://doi.org/10.22203/eCM.v021a29

Patel, P., Irvine, S., McEwan, J. R., \& Jayasinghe, S. N. (2008). Bio-protocols for directly forming active encapsulations containing living primary cells. Soft Matter , 4 (6), 1219. https://doi.org/10.1039/b718866h

Reboredo, J. W., Weigel, T., Steinert, A., Rackwitz, L., Rudert, M., \& Walles, H. (2016). Investigation of Migration and Differentiation of Human Mesenchymal Stem Cells on Five-Layered Collagenous Electrospun Scaffold Mimicking Native Cartilage Structure. Advanced Healthcare Materials , 5 (17), 2191-2198. https://doi.org/10.1002/adhm.201600134

Rnjak-Kovacina, J., \& Weiss, A. S. (2011). Increasing the pore size of electrospun scaffolds. Tissue Engineering Part B: Reviews ,17 (5), 365-372. https://doi.org/10.1089/ten.teb.2011.0235 
Rosell-Llompart, J., Grifoll, J., \& Loscertales, I. G. (2018). Electrosprays in the cone-jet mode: From Taylor cone formation to spray development. Journal of Aerosol Science , 125 (November 2017), 2-31. https://doi.org/10.1016/j.jaerosci.2018.04.008

Sahoo, S., Lee, W. C., Goh, J. C. H., \& Toh, S. L. (2010). Bio-electrospraying: A potentially safe technique for delivering progenitor cells. Biotechnology and Bioengineering ,106 (4), 690-698. https://doi.org/10.1002/bit.22734

Sampson, S. L., Saraiva, L., Gustafsson, K., Jayasinghe, S. N., \& Robertson, B. D. (2013). Cell electrospinning: An in vitro and in vivo study. Small , 10 (1), 78-82. https://doi.org/10.1002/smll.201300804

Stankus, J. J., Guan, J., Fujimoto, K., \& Wagner, W. R. (2006). Microintegrating smooth muscle cells into a biodegradable, elastomeric fiber matrix. Biomaterials , 27 (5), 735-744. https://doi.org/10.1016/j.biomaterials.2005.06.020

Steele, J. A. M., McCullen, S. D., Callanan, A., Autefage, H., Accardi, M. A., Dini, D., \& Stevens, M. M. (2014). Combinatorial scaffold morphologies for zonal articular cartilage engineering. Acta Biomaterialia , 10 (5), 2065-2075. https://doi.org/10.1016/j.actbio.2013.12.030

Townsend-Nicholson, A., \& Jayasinghe, S. N. (2006). Cell electrospinning: A unique biotechnique for encapsulating living organisms for generating active biological microthreads/scaffolds.Biomacromolecules , 7 (12), 3364-3369. https://doi.org/10.1021/bm060649h

van Aalst, J. A., Reed, C. R., Han, L., Andrady, T., Hromadka, M., Bernacki, S., Kolappa, K., Collins, J. B., \& Loboa, E. G. (2008). Cellular Incorporation Into Electrospun Nanofibers. Annals of Plastic Surgery, 60 (5), 577-583. https://doi.org/10.1097/SAP.0b013e318168db3e

Villalona, G. A., Udelsman, B., Duncan, D. R., McGillicuddy, E., Sawh-Martinez, R. F., Hibino, N., Painter, C., Mirensky, T., Erickson, B., Shinoka, T., \& Breuer, C. K. (2010). Cell-seeding techniques in vascular tissue engineering. Tissue Engineering Part B: Reviews ,16 (3), 341-350. https://doi.org/10.1089/ten.TEB.2009.0527

Ward, E., Chan, E., Gustafsson, K., \& Jayasinghe, S. N. (2010). Combining bio-electrospraying with gene therapy: A novel biotechnique for the delivery of genetic material via living cells. Analyst ,135 (5), 10421049. https://doi.org/10.1039/b923307e

Weidenbacher, L., Abrishamkar, A., Rottmar, M., Guex, A. G., Maniura-Weber, K., deMello, A. J., Ferguson, S. J., Rossi, R. M., \& Fortunato, G. (2017). Electrospraying of microfluidic encapsulated cells for the fabrication of cell-laden electrospun hybrid tissue constructs.Acta Biomaterialia , 64 , 137-147. https://doi.org/10.1016/j.actbio.2017.10.012

Xu, T., Binder, K. W., Albanna, M. Z., Dice, D., Zhao, W., Yoo, J. J., \& Atala, A. (2012). Hybrid printing of mechanically and biologically improved constructs for cartilage tissue engineering applications.Biofabrication , 5 (1), 015001. https://doi.org/10.1088/1758-5082/5/1/015001 


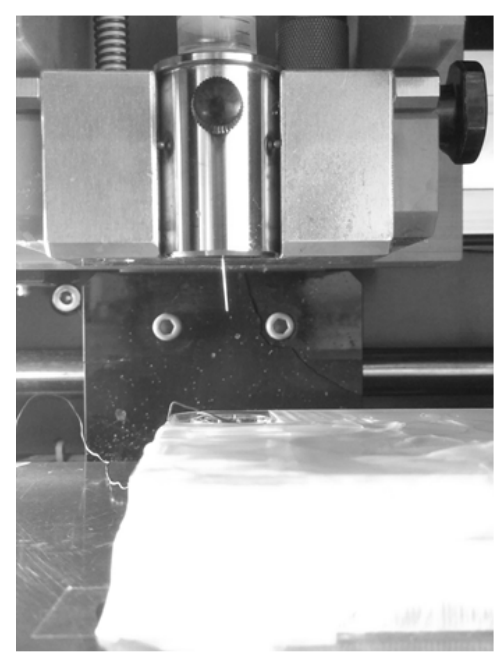

a) Cell suspension

Needles dimensions:

:

$\square$ Applied Voltages:

- 25G (ID $0.26 \mathrm{~mm}$ )

- 27G (ID $0.21 \mathrm{~mm}$ )

- 8 to $16.5 \mathrm{kV}$

- 30G (ID $0.159 \mathrm{~mm}$ )

(Stable cone-jet mode)
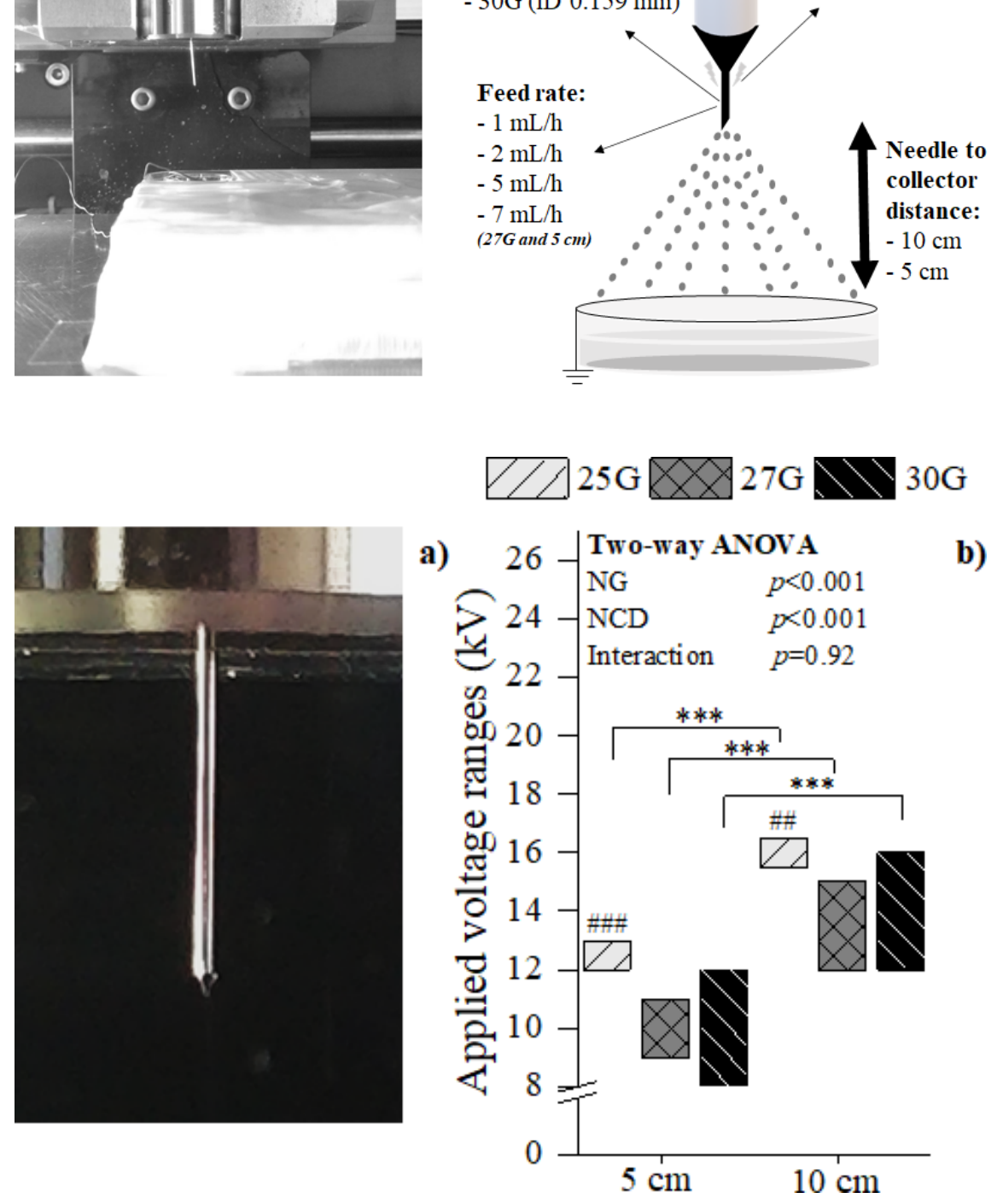

b) 


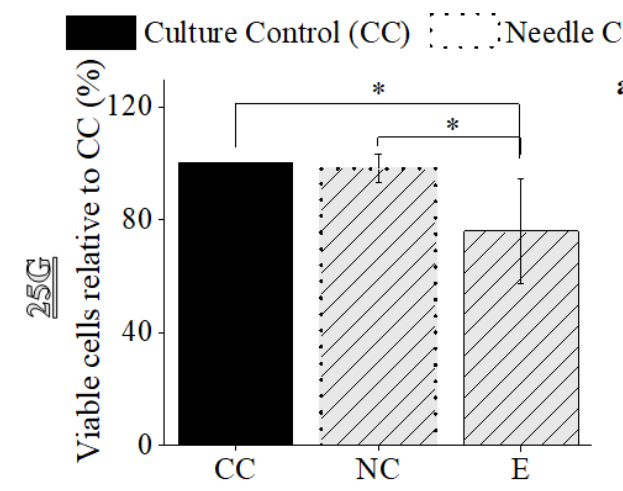

Control (NC)

Electrosprayed cells (E)

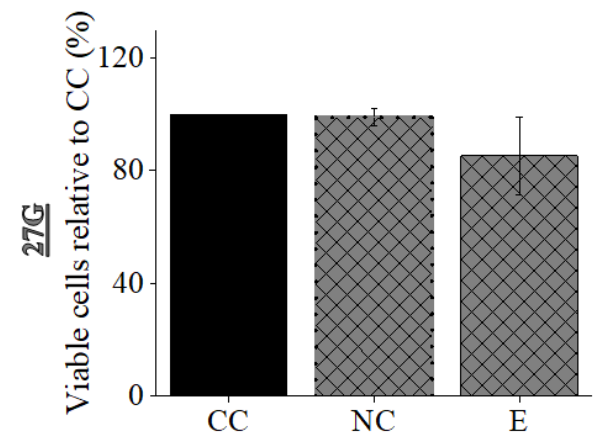

a)

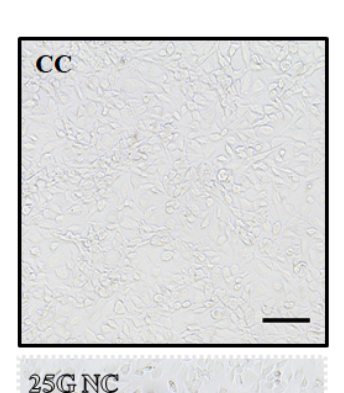

b)
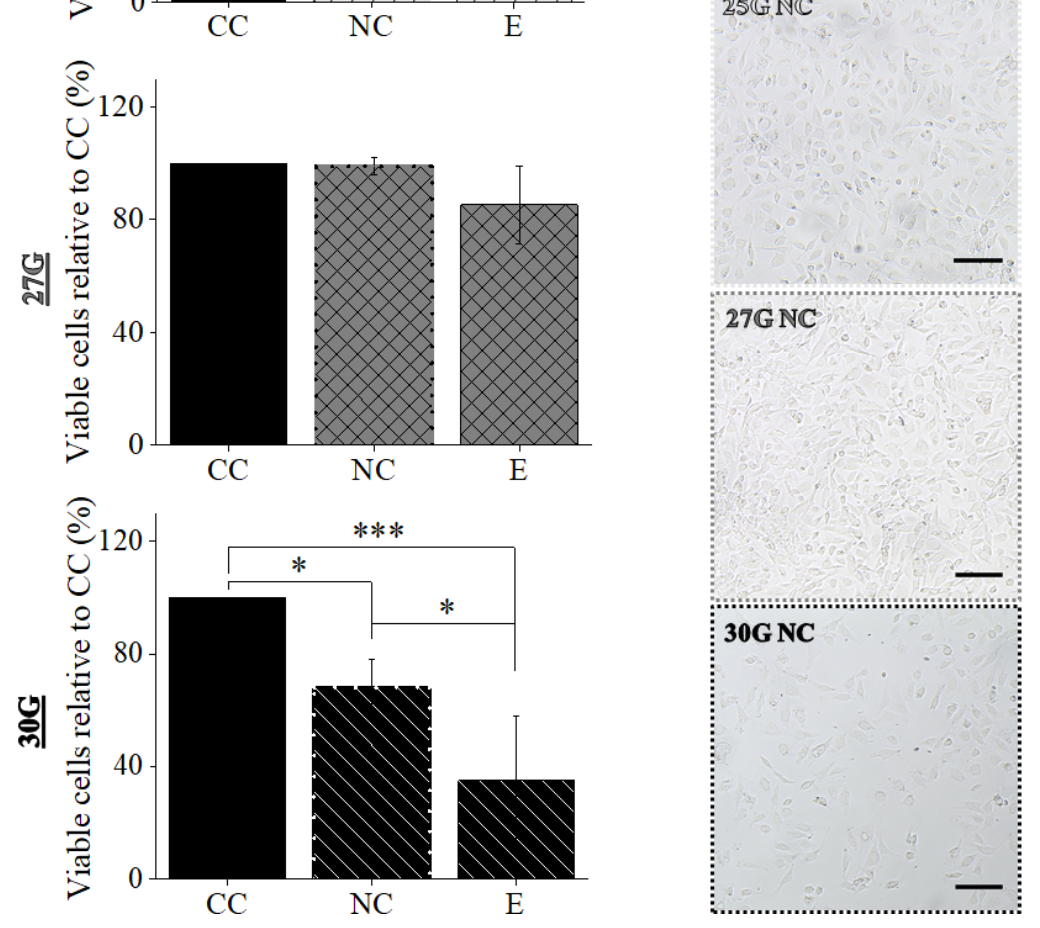

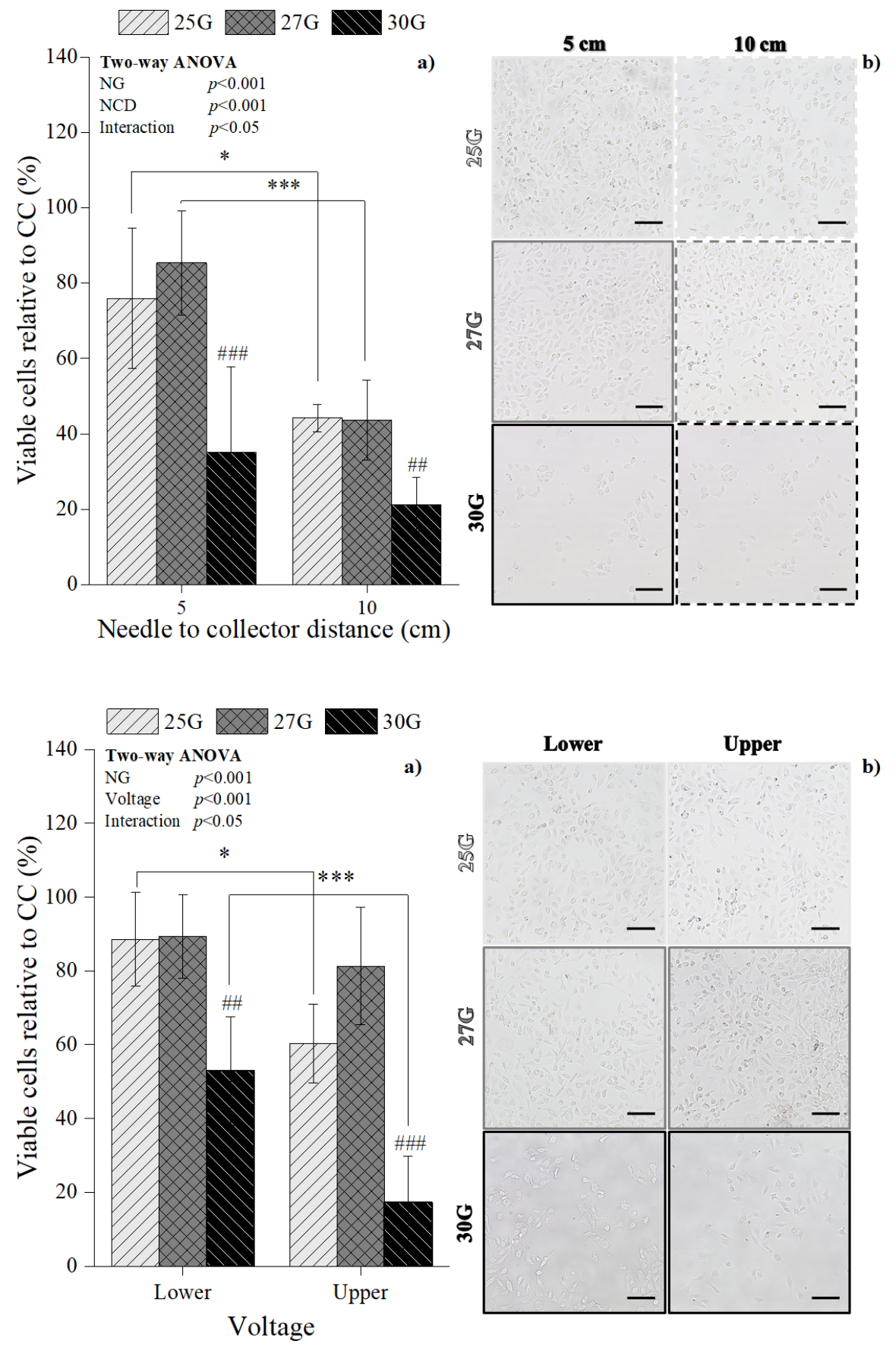

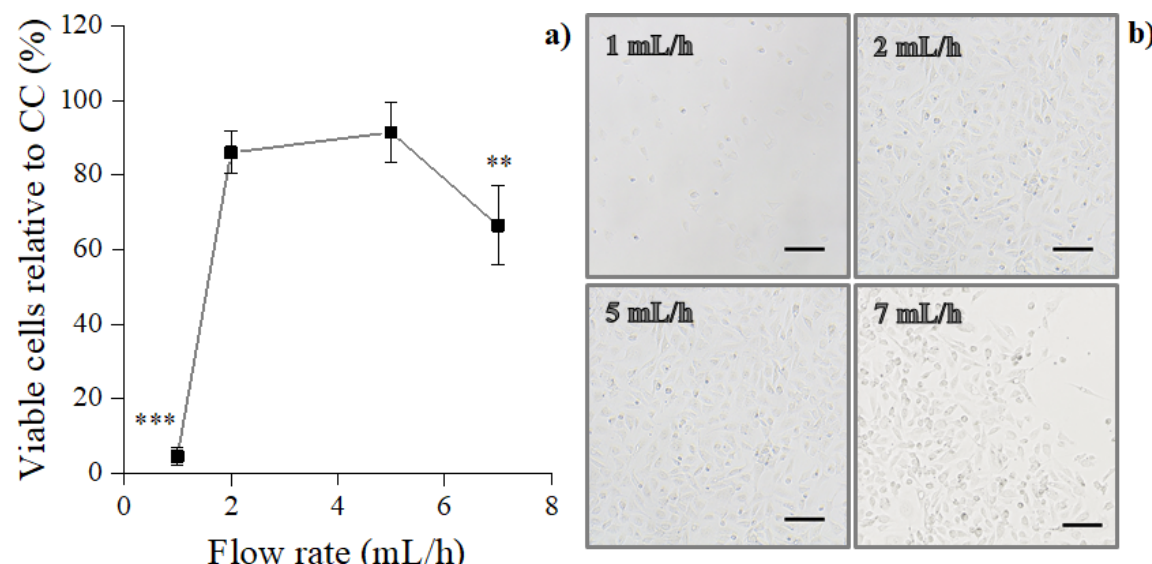

b)

Flow rate $(\mathrm{mL} / \mathrm{h})$ 

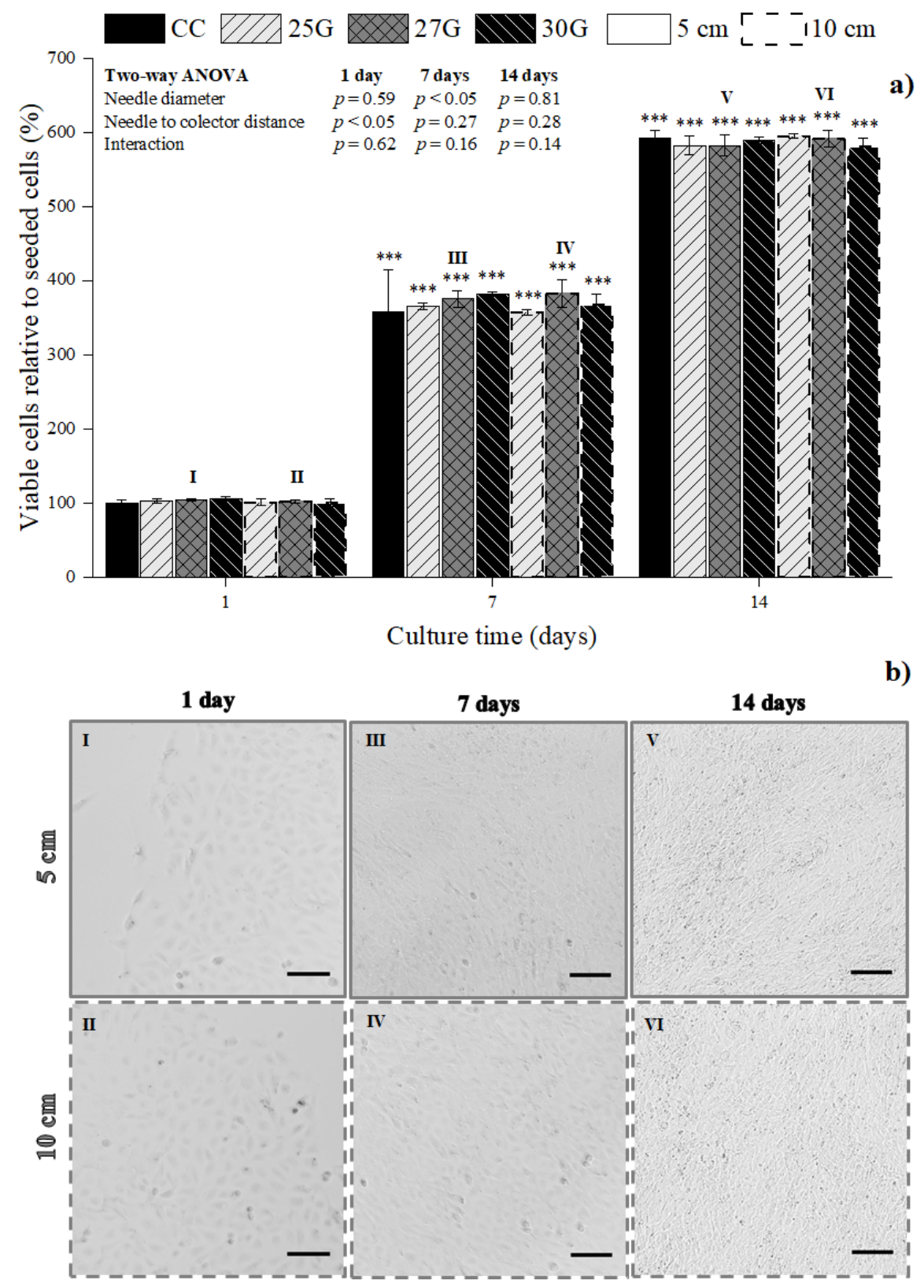